\title{
EDITORIAL
}

\section{Endothelial progenitor cells and coronary artery disease}

\section{S Francis}

Heart 2004;90:591-592. doi: 10.1136/hrt.2003.029942

\section{Endothelial progenitor cells have radically altered the way in which vascular biologists and clinicians think about the genesis, development, and healing of atherosclerotic lesions.}

Correspondence to: Dr Sheila Francis, Cardiovascular Research Unit, Division of Clinical Sciences North, School of Medicine and Biomedical Sciences, University of Sheffield, Sheffield S5 7AU, UK: s.francis@sheffield.ac.uk
$\mathrm{E}$ ndothelial progenitor cells (EPCs) are a subset of pluripotent "stem cells" derived from the bone marrow that can circulate in the blood. Release of EPCs from the marrow occurs in response to chemokines produced as a result of remote injury. The scientific evidence to date suggests that EPCs then home to injury sites, thereby contributing to tissue revascularisation and regeneration. ${ }^{1}$

EPC populations can be isolated and cultured from a number of sources such as CDI4-positive, CD34-positive, and CD133-positive haematopoietic cells from peripheral or fetal cord blood and human bone marrow. Additional reservoirs of EPCs, including the vessel wall itself, may yet be defined. Although the exact molecular characterisation of EPCs is still uncertain, they have been shown to express the endothelial markers von Willebrand factor (vWF), vascular endothelial growth factor-2 receptor (VEGF2R), VEcadherin, PECAM-1 (CD31), Tie 1, Tie 2, and E-selectin among others. ${ }^{1}$ Studies to date have been hampered by the lack of more discriminatory endothelial markers and functional assays to distinguish EPCs from circulating mature vessel wall endothelial cells or haematopoietic cells. The best marker so far appears to be a haematopoietic stem cell marker called AC133 (CD133), a 5-transmembrane glycoprotein of unclear function which is lost in mature adherent endothelial cells. Accordingly, populations of CD34+ EPCs have the molecular signature AC133+ VEGFR2+ and represent functional endothelial precursors. ${ }^{2}$

The numbers of EPCs in the circulation can be increased by a variety of means-for example, vascular trauma, ${ }^{3}$ physical training, ${ }^{4}$ cytokines, ${ }^{5}$ drugs $^{6}$ and other as yet unknown stimuli. Indeed, one might predict that production and lifespan of EPCs might also be wholly or in part dependent on the individual genotype of genes influencing endothelial cell lifespan.

Mobilisation of precursors from the bone marrow depends on the activation of metalloproteinases that act to release EPCs from the stroma and upregulation of adhesion molecules that facilitate trafficking of the EPCs into the circulation via the sinusoids. VEGF and G-CSF are known to be principal factors in this regard. $^{7}$

\section{TRANSDIFFERENTIATION}

The capacity of EPCs to transdifferentiate into other cell types is likely to be an important property for their regenerative function. It has already been shown in rodents that EPCs under specific permissive conditions can become vascular smooth muscle cells (VSMC). ${ }^{8}$ Bone marrow precursors differentiated into VSMC have also been identified in histological samples of human atheroma from sex mismatched bone marrow transplant patients with coronary artery disease. ${ }^{9}$ Once the genetic and cellular mechanisms that influence transdifferentiation are clear, the biological potential of EPCs could be exploited further for repair purposes.

Why should we be excited about EPCs? Quite simply, because they have radically altered the way in which vascular biologists and clinicians think about the genesis, development, and healing of atherosclerotic lesions. As a result, in addition to understanding the local environment of the arterial wall, we should now consider the ability of EPCs to modulate lesion development. Although there is evidence that EPCs integrate into injury sites in mouse models, ${ }^{8}$ seed implanted coronary devices, ${ }^{10}$ and damage large or adventitial vessels after cardiac transplantation in humans, ${ }^{11}$ the mechanisms by which they recognise damaged and dysfunctional endothelium, whether they divide, migrate or transdifferentiate before or after they enter the vessel wall, remain unclear.

\section{CARDIOVASCULAR RISK}

Furthermore, recent literature has demonstrated a clear link between circulating numbers of EPCs and cardiovascular risk. Despite the relatively crude and various methods of isolation, characterisation, and subsequent culture of EPCs, the reports to date show a decrease in EPCs with cumulative cardiovascular risk. ${ }^{12}$ In this issue of Heart, Eizawa and colleagues ${ }^{13}$ show that diabetes is a significant independent predictor of decreased numbers of CD34-positive cells in the peripheral blood of patients with stable coronary artery disease compared with age matched controls.

There are still questions. Among the most pressing are for the clear use of the acronyms that define EPCs in all their various guises, along with identification of unambiguous unique surface markers and genome expression that define the cell's position within the endothelial cell maturation pathway. Laboratory conditions for

Abbreviations: EPC, endothelial progenitor cell;

VEGF2R, vascular endothelial growth factor-2 receptor; VSMC, vascular smooth muscle cells 
the ideal growth and expansion of EPCs, knowledge of the homing signals to normal and diseased vessel walls, genetic propensity for decreased production of EPCs, transduction of EPC with key regulators of differentiation, and ligand targeting of EPCs for delivery to injured sites within the vasculature are all key stimulating research areas.

Should we be at all cautious about the future use of EPCs? Perhaps, but then, not since the Russell Ross "response to injury hypothesis" for the development of the atherosclerotic lesion ${ }^{14}{ }^{15}$ has vascular biology experienced such a paradigm shift in its thinking on arterial wall repair.

I strongly believe that we should seize this opportunity to modify our current thinking on the pathobiology of arterial disease towards the restoration of endothelial function by EPC based therapies.

\section{REFERENCES}

1 Rafii S, Lyden D. Therapeutic stem and progenitor cell transplantation for organ vascularization and regeneration. Nat Med 2003;9:702-12.

2 Peichev M, Naiyer AJ, Pereira D, et al. Expression of VEGFR-2 and AC133 by circulating human CD34(+) cells identifies a population of functional endothelial precursors. Blood 2000;95:952-8.

3 Gill M, Diad S, Hattori K, et al. Vascular trauma induces rapid but transient mobilization of VEGFR2(+)AC133(+) endothelial precursor cells. Circ Res 2001;88:167-74
4 Laufs U, Werner N, Link A, et al. Physical training increases endothelial progenitor cells, inhibits neointima formation, and enhances angiogenesis. Circulation 2004; 109:220-6.

5 Takahashi T, Kalka C, Masuda H, et al. Ischemia- and cytokine-induced mobilization of bone marrow-derived endothelial progenitor cells for neovascularization. Nat Med 1999;5:434-8.

6 Vasa M, Fichtlscherer S, Adler K, et al. Increase in circulating endothelial progenitor cells by statin therapy in patients with stable coronary artery disease. Circulation 2001;103:2885-90.

7 Rafii S, Meeus S, Dias S, et al. Contribution of marrow-derived progenitors to vascular and cardiac regeneration. Semin Cell Dev Biol 2002;13:61-7.

8 Sata M, Saiura A, Kunisato A, et al. Hematopoietic stem cells differentiate into vascular cells that participate in the pathogenesis of atherosclerosis. Nat Med 2002;8:403-9.

9 Caplice NM, Bunch TJ, Stalboerger PG, et al. Smooth muscle cells in human coronary atherosclerosis can originate from cells administered at marrow transplantation. Proc Natl Acad Sci U S A 2003;100:4754-9.

10 Rafii S, Oz MC, Seldomridge JA, et al. Characterization of hematopoietic cells arising on the textured surface of left ventricular assist devices. Ann Thorac Surg 1995;60:1627-32

11 Simper D, Wang S, Deb A, et al. Endothelial progenitor cells are decreased in blood of cardiac allograft patients with vasculopathy and endothelial cells of noncardiac origin are enriched in transplant atherosclerosis. Circulation 2003; 108:143-9.

12 Hill JM, Zalos G, Halcox JP, et al. Circulating endothelial progenitor cells, vascular function, and cardiovascular risk. N Engl J Med 2003;348:593-600.

13 Eizawa T, lkeda U, Murakami Y, et al. Decrease in circulating endothelial progenitor cells in patients with stable coronary artery disease. Heart 2004:90:685-6.

14 Ross R. The pathogenesis of atherosclerosis: a perspective for the 1990s. Nature 1993;362:801-9.

15 Ross R. Atherosclerosis-an inflammatory disease. N Engl J Med 1999:340:115-26.

\section{IMAGES IN CARDIOLOGY}

\section{Twiddler's syndrome in a biventricular implantable cardioverter-defibrillator}

$\mathrm{T}$

his 76 year old man had a biventricular implantable cardioverter-defibrillator (ICD) implanted on 14 March 2003 for heart failure and ventricular tachycardia (VT) caused by ischaemic heart disease. At first follow up his ECG suggested right ventricular pacing only. Chest $x$ ray confirmed that the ICD had been rotated clockwise through almost $360^{\circ}$. The left ventricle (LV) lead was displaced with loss of LV pacing, as was the active fixation atrial lead. The patient admitted to rubbing the pacemaker can with a clockwise rotation while washing, which we presume resulted in the system displacement. The leads were repositioned and the device re-implanted. He has since remained well with biventricular pacing.
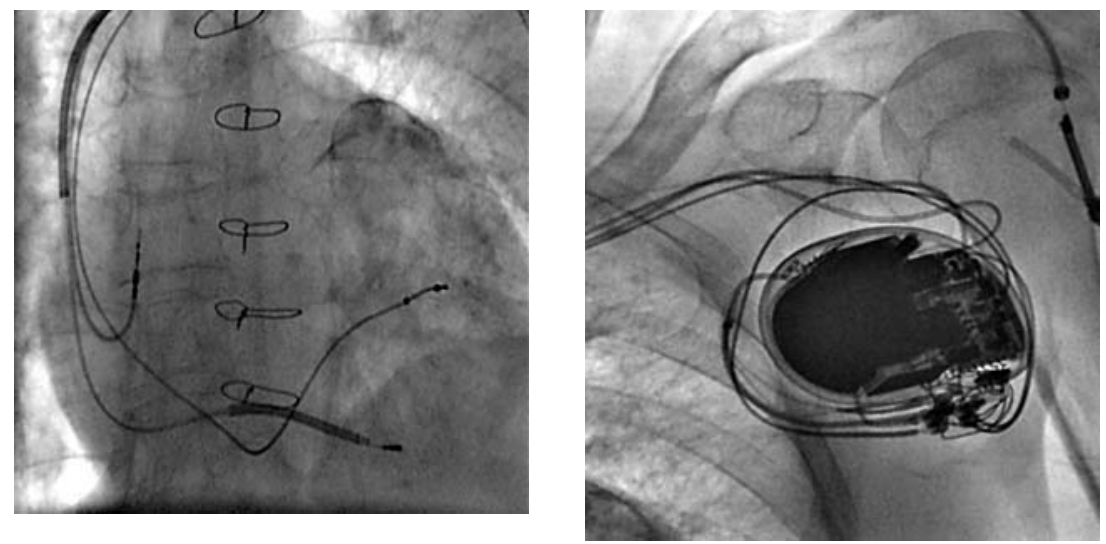

E J Shepherd, J M McComb theshepherdfamily@tiscali.co.uk
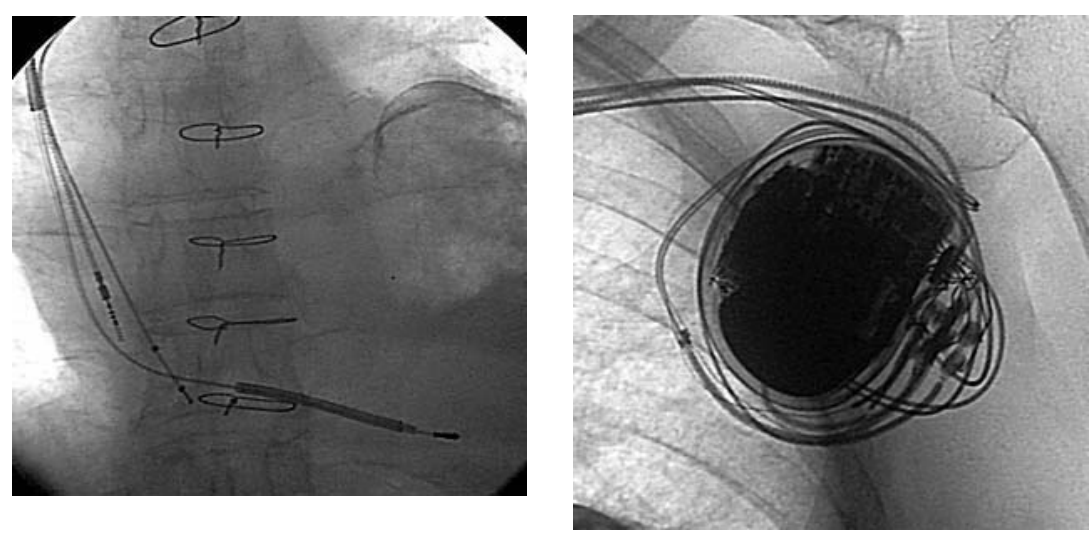